\title{
CHRISTIAN On the Site, Ground NEUHÄUSER and Scope of Justice
}

\section{Review of: Kok-Chor Tan, Justice, Institutions and Luck (Oxford: Oxford University Press, 2012).}

In his very interesting and highly recommendable book, Kok-Chor Tan provides his answers to three crucial questions for any theory of egalitarian justice, namely: Where does it matter? Why does it matter? And among whom does it matter? Tan argues for institutional luck egalitarianism with a global scope and defends it against three objections. The first objection is that an institutional focus is not enough and that an egalitarian ethos is also needed. The second is that a democratic justification of egalitarianism is preferable to the luck egalitarian approach. The third objection is that justice is dependent on state structures and therefore cannot be global in scope. Tan's defence of his position against these three charges is well considered and deliberate. Moreover, he lays out his argumentation very carefully, and proceeds step by step in a highly accessible style. Tan thereby manages to bring two virtues together that are not easily combined. Because of its style, the book can function as an introduction to the debate. And because of their wit and rigour, Tan's arguments about the site, ground, and scope of justice provide a benchmark for anyone taking a stance regarding these issues.

Tan argues that the site of justice consists in the background institutions of society and not the personal decisions and conduct of individuals. Accordingly, individuals do have duties of justice, but those duties are directed at supporting and maintaining just background institutions. The reason for this limitation of the site of justice to the background structure is twofold. First, "with just institutions firmly in place, individuals can freely pursue their ends within the rules of those institutions" (p. 24). Second, this personal space is important, because it preserves value pluralism. People can freely pursue their own ends and different conceptions of the good, which do not have to be egalitarian in nature, within this just background structure. The idea is that focusing on background institutions supports value pluralism by leaving maximum room for different conceptions of the good. This is a strong argument in favour of institutions as the site of justice. 
However, a problematic implication of Tan's argument is that the intended 'division of labour' (between just institutions and individual value pluralism) only works when the background structure really is just - as Tan indeed acknowledges. It is certainly legitimate to limit an argument regarding the site of justice to ideal circumstances. However, it would be interesting to know what Tan has to say to the following consideration. Assuming that societies are not static, but constantly changing in their structure, including their basic structure, the background institutions will need to be continuously adjusted to the demands of justice. This would be a continuous process and not an occasional event, as Tan seems to think. If this is true, then ideal circumstances of justice are not an actual and constant state of affairs, but rather an idealized objective. Given that individuals do have a duty to support and maintain a just background structure, this individual duty might then be very demanding, so that the division of labour that Tan intends never really materializes. The constant requirements of maintaining just background structures may well trump almost all personal goals. Depending on how great the current injustice in the background institutions is, people might also have interactional duties of justice in order to compensate for the impairments of the background structure.

Having argued in favour of an institutional conception of egalitarian justice on grounds of value pluralism, Tan then defends this position against an argument brought forward by Gerald A. Cohen. ${ }^{1}$ Cohen argues that demands of justice should not be limited to the basic structure of society, but should also be understood as interactional in nature. Otherwise the problem of extra-incentives for the talented emerges. Talented people can use their talent as leverage to ask for extra-incentives in money. They have this power, because they can threaten to stop using their talents for the benefit of society. For instance, instead of working as surgeons, they become poets. Tan thinks that Cohen's complaint is understandable, but cannot be helped. The reason is that only through extraincentives can an important dilemma be solved. The problem, as he writes, "is the combined one of how to achieve equality and improving the situation of the disadvantaged while protecting occupational freedom" (p. 71). A talented person might be willing to work as a surgeon instead of doing poetry or anything else of more personal interest, if she is offered more money. Given that this arrangement is to the advantage of the worst off, because surgeons are more needed than poets, as Tan argues, society should allow for extra-incentives of this kind. The only other solution would be to give up the principle of occupational freedom and Cohen himself is not willing to 'enslave the talented' in this way.

1 See Gerald A. Cohen, 'Where the Action Is: On the Site of Distributive Justice', Philosophy \& Public Affairs 26/1 (1997), 3-30 and Gerald A. Cohen, Rescuing Justice and Equality (Cambridge/MA: Harvard University Press, 2008). 
I am not so sure how convincing this argument is to someone arguing for interactional justice. If there really were a small group of especially talented people who would much prefer to do other things instead of having useful occupations, and if they could only be persuaded to work for the benefit of all by offering them a lot more money, then this argument would be correct. However, I think that these are rather large claims. Talk of the 'talented few' has to be well-grounded on empirical terms, and I am not sure that it is or can be. Moreover, there is the problem of conflicting incentives, well known in behavioural economics, and it would be interesting to know what Tan has to say to this. According to behavioural economic research people are willing to do certain things for altruistic reasons, when monetary incentives are absent; they pick up their children from kindergarden rather punctually or they regularly donate blood. ${ }^{2}$ Once monetary incentives are in place, however, many people give up this altruistic behaviour, forgoing money in favour of convenience. Moral and monetary incentives seem to cancel each other out in those cases and the same might be true for occupational choices. If that is the case, once an egalitarian ethos is in place, more talented people might be willing to do beneficial work for moral reasons and monetary incentives might even dissuade them from doing so.

In the second part of the book, Tan develops his conception of luck egalitarianism. This approach to justice is concerned with the effects of luck on the distribution of goods and resources among persons. Tan talks of goods and resources, but maintains that his account is neutral regarding the equality of what question. The basic idea of luck egalitarianism is that a just distribution should be luck insensitive but choice sensitive, where luck is understood as including all kinds of circumstantial factors. So understood, luck egalitarianism is a tool to evaluate inequalities and to justify corrective or preemptive responses to those inequalities that are due to luck. Tan very carefully argues for a modest account of luck egalitarianism that is limited to questions of distributive justice and to the way background institutions deal with natural contingencies. Institutions should not convert natural contingencies into social advantages or disadvantages for persons. Moreover, Tan understands luck egalitarianism as a grounding principle of justice and not a substantive principle of distribution, and as a grounding idea, he argues, it is compatible with different substantive principles, including the difference principle, which he favours.

Tan argues for a modest account of institutional luck egalitarianism as a grounding principle of distributive justice for the background structure, because

2 Steven D. Levitt/Stephen J. Dubner, Freakonomics: A Rogue Economist Explores the Hidden Side of Everything (New York: Harper Collins, 2009); Lorenz Goette/Alois Stutzer/ Michael Zehnder, 'Active Decisions and Prosocial Behaviour: A Field Experiment in Blood Donation', Economic Journal 121/556 (2011), 476-493. 
he thinks that only such a modest account can meet three forceful criticisms raised against luck egalitarianism. The first criticism is that luck egalitarianism has absurd moral consequences, especially since all differences in good and bad luck would have to be corrected, for example the correction of ugliness through plastic surgery. Moreover if someone finds herself in dire circumstances because of her bad choices, there is no reason to help her out of her misery on grounds of luck egalitarianism. Tan replies that in his version of luck egalitarianism, there is no need to correct all differences in luck, because only institutional advantages and disadvantages are relevant. If ugliness is not converted into an institutional disadvantage, there is no issue of distributive justice. He further argues that luck egalitarianism is a theory of distributive justice, and there may well be other reasons to assist the needy, grounded, for example, in human rights. Tan's reply is convincing, but one wonders if he somewhat misrepresented the criticism brought forward by democratic egalitarians like Elizabeth Anderson. ${ }^{3}$ Her problem is not only that the very needy are left alone, but also that luck egalitarianism allows for too much inequality due to bad choice so that not everyone has an equal democratic standing. According to democratic egalitarianism, the acceptable space of inequality might be smaller than luck egalitarianism allows for. Tan does not answer this complaint, but I think he needs to; otherwise his version of luck egalitarianism might be harmful to democracy and its proper functioning.

The second criticism of luck egalitarianism is that it is implausibly asocial and does not set out to prevent unequal relations, but only to compensate for them in retrospect. Tan replies that this criticism simply misinterprets luck egalitarianism as a substantive principle of distribution, which it is not, at least in his version. Luck egalitarianism as a grounding principle of justice can be coupled with a distributive principle that is not only compensatory in nature, but also alters the basic structure by restructuring economic entitlements. Moreover, he claims that luck egalitarianism favours democratic relations, but does not presuppose social cooperation and therefore is wider in scope than democratic equality.

The third criticism is that luck egalitarianism needs a metaphysical defence of the luck and choice distinction. Without such a defence it lacks philosophical depth. Tan replies that this is not the case, and instead only a social distinction of luck and choice is needed, based on "social conventions, common understandings and practices" (p. 137). I do not think that this reply is very convincing. Maybe it is true that no full-blown metaphysics of free will is needed. But surely something more can and should be said about luck and choice than merely pointing at conventions. For example, if in the US people normally believe that performance in school and college is due to choice, then for luck egalitarianism that seems to

3 Elizabeth Anderson, 'What Is the Point of Equality?', Ethics 109 (1999), 287-337. 
be a fact, despite evidence from sociological research and arguments in social theory, as for example those developed by Pierre Bourdieu. ${ }^{4}$ The trouble with this account can also be seen in some of Tan's own examples. He states, for instance, that it is due to bad luck when someone is struck by lightning, while it is choice when someone loses everything in gambling. However, the first person might have chosen to walk in a thunderstorm, in full knowledge of the risk. The second person on the other hand might have had a lot of extremely bad luck in her life, coming to see it as a kind of gamble and responding by doing the only sensible thing left for her, which is to submit to this gamble of her life. It is possible these difficulties could be worked out, but any account of luck egalitarianism based on a social conception of luck and choice needs to be backed up by a well-considered and critical sociological theory of luck and choice, not only by conventions, because conventions may themselves be based on unjust intuitions.

In the third section of the book Tan argues that institutional luck egalitarianism has to be global in scope. The reason is that there are global and globally accepted national institutions that turn luck into social advantages and disadvantages, for instance the distribution of resources and memberships in states. According to his account, it is therefore necessary that the scope of distributive equality be global as well. Tan then considers two arguments in favour of limiting questions of distributive justice to the state level. The first argument is that states coerce members politically, which can only be legitimate if a scheme of distributive justice is in place. Tan replies that the global structure of institutions is also coercive, and is likewise in need of legitimation. He argues against Thomas Nagel that legitimation should not be dependent on the special standing citizens have, because this would take away protection from those who need it most, which is counter-intuitive. The second argument depends on the idea of a special form of cooperation taking place within the state. Here Tan points to the idea of social cooperation on the global level and asks why cooperation within the state should be special. The only reason could be a special normative status of nationality, which he argues does not exist, because nationality is arbitrary.

Tan considers three arguments against his claim that nationality is unimportant for global equality. The first argument is that nationality is arbitrary, but not irrelevant, like special needs are arbitrary, but morally relevant. Here Tan answers that attending to special needs is designed to render them irrelevant and the same counts for nationality - it too should be rendered irrelevant. The second argument depends on the idea of special obligation to others with whom we have a special relationship, like family members. Tan answers that those special obligations can only arise within a just background structure and then

4 Pierre Bourdieu, Language and Symbolic Power (Cambridge: Polity, 1991). 
it indeed is possible to have special obligations towards family members and fellow citizens within this structure. The third argument, which he rejects, is that even if nationality is arbitrary, global justice does not have to be egalitarian, but can be sufficientarian, for instance. Here Tan simply points at his account of luck egalitarianism as a starting point. The third chapter is the least persuasive in the book, because Tan simply presupposes his version of institutional luck egalitarianism. It is a consequence of this account that distributive equality has to be global in scope. However, all those who find the idea of global distributive equality unattractive might take this as a reason to doubt the intuitive plausibility of luck egalitarianism, and it is not clear what argument Tan could make in order to lessen those doubts.

Tan ends his book with the discussion of a number of minor issues and the hope that his "discussion of the site, ground, and scope of equality can have some bearing on our understanding of equality's pattern and currency" (p. 197), although he has not discussed those questions directly. The answer to this question is a definite yes, since his book is very useful for broadening our understanding of luck egalitarianism and of justice per se.

Dr. Christian Neuhäuser

Universität Luzern

email:christian.neuhaeuser@unilu.ch

\section{the global justicenetuork}

